\title{
Las potencias emergentes en los espacios multilaterales de negociación de hegemonía noratlántica: la cuestión energética y las patentes farmacéuticas
}

\author{
Emerging powers in the multilateral negotiation spaces \\ of North-Atlantic hegemony: the energy issue and the \\ pharmaceutical patents
}

As potências emergentes nos espaços multilaterais de negociação de hegemonia do Atlântico Norte: a questão energética e as patentes farmacêuticas

\author{
iD Clarisa Giaccaglia \\ Universidad Nacional de Rosario, Rosario, Santa Fe, Argentina \\ clagiaccaglia@yahoo.com.ar \\ (iD) María Noel Dussort ${ }^{2}$ \\ Universidad Nacional de Rosario, Rosario, Santa Fe, Argentina \\ maria.dussort@fcpolit.unr.edu.ar
}

Resumen: La agenda internacional se ha convertido en un espacio clave para el desarrollo de la política mundial, constituyendo un ámbito dinámico por el cual una creciente cantidad de temáticas han adquirido carácter de "interés global". La falta de una jerarquía clara entre las múltiples cuestiones ha implicado que el diseño de la agenda internacional dependa de los actores involucrados en el proceso. En este marco, el presente artículo tiene por objeto analizar el rol de las potencias emergentes en los

\footnotetext{
1 Investigadora adjunta del Consejo Nacional de Investigaciones Científicas y Técnicas (CONICET). 2 Becaria posdoctoral del Consejo Nacional de Investigaciones Científicas y Técnicas (CONICET).
} 
espacios multilaterales de negociación internacional tomando en consideración dos temas de la agenda global: energía y patentes farmacéuticas, con el fin de reconocer si se han convertido en reforzadoras o en cuestionadoras de los espacios multilaterales de negociación de hegemonía noratlántica.

Palabras claves: Potencias emergentes. Potencias tradicionales. Negociaciones multilaterales. Energía. Patentes farmacéuticas.

Abstract: The international agenda has become a key space for the development of world politics constituting a dynamic field where a growing amount of themes has acquired a character of "global interest". The lack of a clear hierarchy regarding the numerous topics means that the international agenda depends on the actors involved in the process. Within this framework, this article aims to analyze the list of emerging powers in the multilateral spaces of international negotiation taking into account two themes of the global agenda: energy and pharmaceutical patents. The purpose of the research is to recognize if emerging powers have reinforced or questioned the multilateral negotiating spaces of North-Atlantic hegemony.

Keywords: Emerging powers. Traditional powers. Multilateral negotiations. Energy. Pharmaceutical patents.

Resumo: A agenda internacional se tornou um espaço chave para o desenvolvimento da política mundial, constituindo um âmbito dinâmico, onde uma crescente quantidade de temáticas tem adquirido caráter de "interesse global". A falta de uma hierarquia clara entre as numerosas questões tem feito com que o desenho da agenda internacional dependa dos atores envolvidos no processo. Nesse cenário, o presente artigo tem por objetivo analisar o rol das potências emergentes nos espaços multilaterais de negociação internacional levando em consideração dois temas da agenda global: energia e patentes farmacêuticas. O objetivo é reconhecer se ditas potências têm se transformado em reforçadoras ou 
questionadoras dos espaços multilaterais de negociação da hegemonia do Atlântico Norte.

Palavras-chave: Países emergentes. Potências tradicionais. Negociações multilaterais. Energia. Patente farmacêutica.

Data de recebimento do artigo: 03/03/2019

Data de aprovação do artigo: 07/05/2019 


\section{Introducción}

Los diversos, y en muchos casos sorpresivos, cambios ocurridos en el tiempo reciente en el escenario internacional han vuelto difícil el análisis de una política mundial compleja y con altos grados de incertidumbre. En ese contexto, la agenda internacional se ha transformado en un espacio clave para el desarrollo de la política mundial, constituyendo un ámbito dinámico por el cual una creciente cantidad de temáticas han adquirido carácter de "interés global". La importancia de un tratamiento internacional de múltiples cuestiones que tradicionalmente se restringían a los ámbitos nacionales tuvo sus inicios en la década del setenta, producto, entre otros factores, del auge de las organizaciones no gubernamentales (ONGs) y, en consecuencia, hubo el desarrollo de agendas provenientes de la sociedad civil internacional.

Esta relevancia se acentuó en los años noventa, a raíz de la finalización de la Guerra Fría y de un creciente dinamismo en las organizaciones internacionales gubernamentales, que pudieron dejar atrás cierta parálisis que había caracterizado a las negociaciones multilaterales en un marco bipolar. Finalmente, la discusión de temáticas de orden global se profundizó notablemente a comienzos del siglo XXI, al producirse la aparición de las llamadas potencias emergentes, las cuales empezaron a tener una participación cada vez más activa en la discusión de los temas de la agenda multilateral.

La falta de una jerarquía clara entre las múltiples cuestiones ha implicado que el diseño de la agenda internacional dependa de los actores involucrados en el proceso. Desde una perspectiva realista, se observa que son las pujas de poder entre los actores más relevantes las que definen la agenda internacional. Las potencias desarrollan un papel decisivo no sólo en las votaciones o en la elaboración de políticas, sino también en la definición de los temas que deben estar al frente de las negociaciones, desestimando aquellos que puedan afectarlos y promoviendo aquellos que puedan favorecerlos (DREZNER, 2007; HOLBRAAD, 1989; IAN, 2004; SCHWELLER, 1994). 
La discusión de la agenda internacional, a inicios del siglo $X X I$, se ha caracterizado por un "multilateralismo revisionista" de la mano de potencias emergentes que exigen cambios tanto en las normas ya establecidas como en el temario a debatir (SANAHUJA, 2017). Durante la primera década del siglo XXI, este multilateralismo revisionista adquirió fundamentalmente dos modalidades. Por un lado, el bloqueo de ciertas negociaciones como en la Conferencia ministerial de la OMC en Cancún, en 2003, o en la Conferencia de Partes de Cambio Climático, en 2009, por sólo mencionar algunos ejemplos. En esta primera instancia, los nuevos poderes intervinientes se restringieron a cumplir un rol de "veto players", negándose a debatir un temario impuesto por las potencias tradicionales. Por otro lado, una segunda modalidad de acción estuvo asociada a la creación de iniciativas propias, las cuales fueron progresando desde mecanismos informales de coordinación hacia esquemas más institucionalizados. De esta forma, las potencias emergentes comenzaron definiendo sus propios "G" (G20/G33/G90 en la Organización Mundial del Comercio (OMC); el Foro India, Brasil, Sudáfrica (IBSA); el grupo ad-hoc en las negociaciones del acuerdo de París entre Brasil, Sudáfrica, India y China (BASIC) y el Foro Brasil, Rusia, India, China y Sudáfrica (BRICS) para afrontar, en tiempos más recientes, la creación de nuevas instituciones internacionales, como el Nuevo Banco de Desarrollo o el Banco Asiático de Inversión en Infraestructura (BAll), la Organización de Cooperación de Shanghai (OCS) y la iniciativa china One Belt, One Road (OBOR), entre otras (Giaccaglia, 2018).

En este contexto, cabe preguntarnos: ¿cuál ha sido el rol de las potencias emergentes en los espacios multilaterales de negociación internacional, ámbitos tradicionales de la hegemonía noratlántica? ¿Han verdaderamente desarrollado un accionar revisionista que haya propiciado cambios profundos 0 , al menos, ciertas modificaciones en los esquemas de negociación mundial? Caso contrario, ¿las potencias emergentes han actuado como reforzadoras del orden internacional liberal? Consecuentemente, ¿puede la estructura normativa occidental dominante sobrevivir escindida de sus creadores? 
Sobre la base del método histórico interpretativo, este artículo busca analizar el rol de las potencias emergentes en los espacios multilaterales de negociación internacional tomando en consideración dos temas de la agenda global: energía y patentes farmacéuticas.

A modo de hipótesis de trabajo sostenemos que, en el marco de los espacios multilaterales de negociación internacional, las potencias emergentes han intentado llegar a acuerdos con las potencias tradicionales, aceptando ideas dominantes de la tradicional estructura de poder global, de hegemonía noratlántica. No obstante, las potencias emergentes han tendido a resistir y/o propiciar cambios en los esquemas decisorios vigentes frente a normativas desfavorables, con el objeto de reforzar sus cuotas de poder mundial procurando reglas de juego que puedan generarles beneficios. De todas maneras, aun considerando aquellos casos de accionar revisionista, las modificaciones implementadas no han significado transformaciones trascendentales en la gobernanza mundial, sino que han actuado como reforzadores del orden internacional liberal. Es decir, se han preservado las características esenciales de la llamada Pax Americana ${ }^{3}$-sus instituciones, reglas y normas- aun cuando sus hacedores se encuentren atravesando procesos de declive relativo de poder mundial.

Desde un punto de vista teórico, resulta necesario precisar la conceptualización de dos nociones teóricas claves para este trabajo: potencias tradicionales y potencias emergentes. Por potencias tradicionales se entiende a aquellas que participaron activamente en la configuración del orden internacional post Segunda Guerra Mundial, que gravitaron dentro de la órbita de influencia capitalista y que posteriormente se agruparon en torno al G-7 como principal bloque que reunió a los países desarrollados más importantes del mundo. Dicho grupo ha sido encabezado, claro está, por Estados Unidos y, en menor medida, por Europa, como principales representantes en las mesas de negociación global (GIACCAGLIA, 2018). Como contrapartida, por potencias emergentes se entiende a un grupo reducido de grandes países

3 La Pax Americana comprende el período de relativa paz en el mundo occidental desde la finalización de la Segunda Guerra Mundial, en 1945, hasta nuestros días, el cual coincide con la posición militar y económica dominante de Estados Unidos. 
en desarrollo que lograron progresivamente diferenciarse del llamado "Sur Global". A inicios del siglo XXI, los emergentes fueron fuertemente identificados en torno al acrónimo BRICS, que en 2009 se convirtió efectivamente en una iniciativa gubernamental conformada por los estados de Brasil, Rusia, India, China y, desde 2011, Sudáfrica (GIACCAGLIA, 2018).

El caso de Rusia requiere una aclaración particular. Teniendo en cuenta que este Estado fue la cabeza del bloque soviético -constituyéndose en una de las superpotencias durante la Guerra Fría- su condición se relaciona con un proceso político que apunta a su "re-emergencia" en el orden mundial. En función de ello, en el presente artículo se excluye a Rusia como caso de estudio, concentrándose en el análisis de los restantes miembros del acrónimo BRICS: Brasil, India, China y Sudáfrica.

El caso de China también merece algunas explicaciones previas. Tomando en consideración los hechos internacionales ocurridos en los últimos años, algunos sectores académicos cuestionan que ella siga siendo identificada como un "emergente" puesto que, sobre todo en función de sus relaciones bilaterales sostenidas con Estados Unidos, su comportamiento estaría dando cuenta de la presencia de un "emergido" antes que de un "emergente". Desde enfoques tradicionalistas se asegura que, a lo largo de la historia, la transición de hegemonía de una potencia a otra ha ocurrido a través de un acontecimiento bélico (ALLISON, 2017). Sin embargo, otras miradas sostienen que no necesariamente China deberá enfrentarse militarmente a Estados Unidos (BUZAN; COX, 2013), sino que podría suscitarse un escenario en el que las disputas se dieran en los distintos espacios de negociación multilateral, tal como se ha comenzado a vislumbrar en las guerras comerciales ocurridas en los últimos dos años.

El trabajo comienza con una aproximación a las discusiones teóricas sobre las potencias emergentes. A continuación, setrabajan dos áreas temáticas en las cuales las potencias emergentes, ya sea por su actuación en conjunto o por su peso individual, han generado ciertos cambios en los procesos negociadores multilaterales. 


\section{Discusiones teóricas: narrativas sobre las potencias emergentes}

La decisión de considerar a Brasil, India, China y Sudáfrica como potencias emergentes obedece a consideraciones provenientes tanto del mundo político internacional como del ámbito académico disciplinar. En otros términos, se debe, por un lado, a las capacidades de poder material relativo que poseen esos estados y, por otro lado, a la consolidación en la narrativa de las Relaciones Internacionales bajo esa categoría. Los dos factores mencionados impactaron de manera directa en la percepción de las elites políticas de los países bajo estudio, generando un mayor sentido de autoconfianza que se tradujo en un accionar externo más asertivo que en el pasado (DUSSORT, 2019, p. 28).

Considerando los aportes del mainstream del campo disciplinar, se observa que tanto los exponentes neorrealistas (MEARSHEIMER, 2001; MEARSHEIMER Y WALT, 2016) como los realistas neoclásicos (SCHWELLER, 2011; ZAKARIA, 2008) y los referentes del institucionalismo liberal (COOPER, 2013; FLEMES, 2007; HURRELL, 2013; IKENBERRY, 2011; NOLTE, 2010) han coincidido en reconocer la presencia de potencias emergentes con crecientes grados de participación en la estructuración del orden internacional contemporáneo. Del mismo modo, la mayoría de ellos acuerdan en que el poder norteamericano está menguando mientras que algunos otros recalcan que si bien Estados Unidos continúa siendo la superpotencia mundial, está siendo desafiada por algunas potencias emergentes, principalmente a nivel económico.

En ese contexto, se adopta la definición de Giaccaglia (2012; 2017, p. 433), por la cual una potencia emergente puede definirse como "aquel Estado que sobre la base de significativas capacidades materiales desarrolla un creciente activismo internacional en ámbitos multilaterales, tanto en su entorno regional más próximo, como en sucesivas y simultáneas negociaciones globales". Asimismo, "se autopercibe y es percibido por otros agentes como 
diferente tanto de las restantes unidades estatales (pequeñas o iguales), como de las grandes potencias tradicionales". La conceptualización propuesta engloba los principales postulados considerados por las corrientes teóricas más importantes de la disciplina de las Relaciones Internacionales, incluyendo tanto elementos materiales (foco de preocupación del realismo), aspectos procedimentales y de dinámica relacional entre agentes (principal interés de los liberales institucionalistas), así como la cuestión de las expectativas recíprocas (tema contemplado especialmente por los constructivistas).

En función de los objetivos aquí planteados, en este artículo se focaliza en el segundo aspecto, referido a la dinámica relacional entre agentes estatales teniendo en cuenta el potencial que esos países han demostrado para modificar el actual orden internacional. En esse sentido, cobran relevancia los aportes del institucionalismo liberal, el cual sostiene que no siempre existe una relación directa entre la posición material que posee un Estado en el escenario global y su nivel de influencia efectiva sobre otros actores, dando más importancia a las interacciones entre los diversos actores. En el seno de los espacios multilaterales de negociación, las potencias emergentes actúan activamente tomando la delantera en la fijación de los temas de la agenda mundial y facilitando la formación de coaliciones negociadoras.

En ese sentido, cabe destacar la producción sobre el rol de las potencias emergentes en los diferentes foros de negociación multilaterales. Las investigaciones realizadas han relevado el gran activismo internacional de esas potencias en diversas áreas temáticas: comercio (CHATURVEDI; SAHA, 2017; HOPEWELL, 2016; NARLIKAR, 2010), finanzas (ARMIJO; ROBERTS, 2014; DREZNER, 2014; WOODS, 2010), seguridad (ABDENUR, 2017; COSTA VAZ, 2006; STUENKEL, 2018; VREŸ, 2017), medioambiente (BUENO RUBIAL, 2017; GIACCAGLIA, 2017; HURRELL; SENGUPTA, 2012; Viola; Franchini; Ribeiro, 2013) y Cooperación Sur-Sur (AYLLÓN PINO, 2011; BRAUTIGAM, 2010; CHATURVEDI, 2012; DUSSORT, 2016; KABUNDA BADI, 2011; LECHINI, 2015; MILANI, 2015; 
MORASSO, 2016; SIDIROPOULOS et al., 2015). En todos los casos, las argumentaciones vertidas en las investigaciones mencionadas apuntan a demostrar una influencia cada vez más significativa de las potencias emergentes en la gobernanza global.

En función del relevamiento realizado, se optó por adentrarse en el análisis del rol de las potencias emergentes en relación a dos temáticas-energía y patentes farmacéuticas-, que han sido abordadas de manera escasa o insuficiente dentro del ámbito disciplinar.

\section{La temática energética, como reforzadora del orden hegemónico noratlántico ${ }^{4}$}

Si tuviéramos que estipular un momento en la historia reciente para determinar el inicio de políticas de coordinación y cooperación energética, deberíamos retrotraernos a los años posteriores al primer shock petrolero, como punto de quiebre del siglo XX. Hace poco más de cuarenta años, las economías avanzadas se erigían como las mayores consumidoras de energía y, a su vez, las mayores importadoras de petróleo crudo. Entre ellas se destacaban Estados Unidos, la URSS, Gran Bretaña, Francia, Alemania y Japón. En esa época, la seguridad energética ( 0 , para ser más precisos, la seguridad de aprovisionamiento petrolero) era una categoría atada a los países desarrollados (MARTíN-MORENO, 2014). No obstante, el siglo XXI viene planteando un nuevo escenario, en donde las cuestiones energéticas han comenzado a estar cada vez más vinculadas a tres países que emergieron por fuera del grupo de las potencias tradicionales, a saber, China, India y Brasil, y que, simultáneamente, vienen desarrollando sus propias estrategias para abordar el problema del acceso a la energía.

Lo dicho anteriormente se debe a que el consumo energético global ha sufrido un crecimiento acelerado desde el 2000 hasta la

4 La temática energética constituye la línea de investigación desarrollada por María Noel Dussort en el marco de su tesis doctoral efectuada con beca del CONICET. 
actualidad. El continente asiático fue la región que mayormente contribuyó con ese incremento y en menor medida América Latina, mientras que regiones altamente consumidoras -como Europa y Norteamérica- se han mantenido relativamente estables (Enerdata online ${ }^{5}$ ).

En particular, China, India y Brasil han contribuido ampliamente para los consumos registrados en sus regiones de pertenencia. Al discriminar entre los doce mayores consumidores de energía mundiales (ver Tabla 1), se puede observar que, en el nuevo siglo, China desplazó a Estados Unidos, India a Japón y Brasil a Canadá y Francia.

Tabla 1 - Evolución de los mayores consumidores de energía del mundo

\begin{tabular}{|c|c|c|}
\hline Puesto & País & $\begin{array}{c}\text { Consumo } \\
\text { Mtoe }\end{array}$ \\
\hline 1 & $\begin{array}{c}\text { Estados } \\
\text { Unidos }\end{array}$ & 2.269 \\
\hline 2 & China & 1.130 \\
\hline 3 & Rusia & 619 \\
\hline 4 & Japón & 518 \\
\hline 5 & India & 441 \\
\hline 6 & Alemania & 337 \\
\hline 7 & Francia & 255 \\
\hline 8 & Canadá & 254 \\
\hline 9 & $\begin{array}{c}\text { Reino } \\
\text { Unido }\end{array}$ & 223 \\
\hline 10 & $\begin{array}{c}\text { Corea } \\
\text { del Sur }\end{array}$ & 190 \\
\hline 11 & Brasil & 188 \\
\hline 12 & Italia & 172 \\
\hline
\end{tabular}

\begin{tabular}{|c|c|c|}
\hline Puesto & País & $\begin{array}{c}\text { Consumo } \\
\text { Mtoe }\end{array}$ \\
\hline 1 & $\begin{array}{c}\text { Estados } \\
\text { Unidos }\end{array}$ & 2338 \\
\hline 2 & China & 2149 \\
\hline 3 & Rusia & 672 \\
\hline 4 & India & 574 \\
\hline 5 & Japón & 514 \\
\hline 6 & Alemania & 328 \\
\hline 7 & Canadá & 270 \\
\hline 8 & Francia & 263 \\
\hline 9 & Brasil & 236 \\
\hline 10 & $\begin{array}{c}\text { Corea } \\
\text { del Sur }\end{array}$ & 227 \\
\hline 11 & $\begin{array}{c}\text { Reino } \\
\text { Unido }\end{array}$ & 211 \\
\hline & & \\
\hline
\end{tabular}

\begin{tabular}{|c|c|c|}
\hline Puesto & País & $\begin{array}{c}\text { Consumo } \\
\text { Mtoe }\end{array}$ \\
\hline 1 & China & 3.105 \\
\hline 2 & $\begin{array}{c}\text { Estados } \\
\text { Unidos }\end{array}$ & 2.201 \\
\hline 3 & India & 934 \\
\hline 4 & Rusia & 744 \\
\hline 5 & Japón & 429 \\
\hline 6 & Alemania & 314 \\
\hline 7 & $\begin{array}{c}\text { Corea del } \\
\text { Sur }\end{array}$ & 296 \\
\hline 8 & Brasil & 291 \\
\hline 9 & Canadá & 287 \\
\hline 10 & Irán & 253 \\
\hline 11 & Francia & 243 \\
\hline 12 & Indonesia & 240 \\
\hline & & \\
\hline
\end{tabular}

Fuente: Dussort (2019).

5 Información extraída de Enerdata, disponible en: https://www.enerdata.net/. Acceso el: 12-03-2019. 
El peso específico de los estados aquí resaltados en el mercado energético es contundente. China es un país de superlativos en el área temática trabajada (BASSO; VIOLA, 2014), ya que no sólo se convirtió en el mayor consumidor de energía en 2009, sino también en el primer productor mundial. En la actualidad, es el segundo mayor consumidor de petróleo, aunque, de acuerdo a la base 'business-as-usual', la Agencia Internacional de la Energía haya pronosticado que el país asiático pasará a ser el principal consumidor de petróleo en 2030, superando a Estados Unidos (IEA, 2018). Asimismo, se destaca como el mayor productor y consumidor de carbón. En cuanto a las fuentes de energía renovables, China lidera las inversiones en tecnologías de baja emisión de carbono, dado que posee la mayor capacidad instalada para la generación de energía eólica, solar e hidráulica a nivel mundial (IEA, 2018).

Por otro lado, India provee con el mayor porcentaje de crecimiento de la demanda energética mundial. Es el cuarto mayor consumidor de petróleo -importando aproximadamente un 80\% del suministro- y se augura que se convertirá en el principal importador de carbón en el futuro cercano (IEA, 2016; 2018). En cuanto a Brasil, un país que no figuraba en el ranking de los mayores productores mundiales de petróleo, desde el descubrimiento del pre-sal irrumpió en el puesto 12, en 2014, escalando hasta el número 10 en 2017 (Enerdata online). Asimismo, se debe tener presente que la aplicación de políticas de inclusión social y de redistribución de la riqueza desde 2003 produjeron que una parte de la población comenzara a acceder a mayores y mejores bienes y servicios, aumentando el consumo energético del país sudamericano.

En definitiva, China, India y Brasil vienen desafiando las posiciones históricas entre productores y consumidores de energía, razón que contribuye a catalogarlos como grandes jugadores energéticos globales y, también, como potencias en ascenso. Ese cambio en la jerarquía mundial comenzó a ser tema de debates entre las potencias tradicionales, con el objeto de brindar cierta previsibilidad al contexto energético global. Algunos organismos 
internacionales, que desde su creación estuvieron compuestos sólo por potencias tradicionales, permitieron la ampliación hacia las potencias emergentes aquí trabajadas, más como una forma de mantener el status quo que como reconocimiento a la transición del sistema internacional.

Ahora bien, en la actualidad no es posible afirmar que la temática energética haya derivado en la conformación de un régimen internacional, bajo la perspectiva de Ruggie (1982) o Krasner (1983). Esto se debe a la existencia de una multiplicidad de organizaciones internacionales y actores de relevancia, quienes la mayoría de las veces no se encuentran coordinados entre sí y que incluso presentan agendas superpuestas.

Históricamente, la gobernanza energética ha estado fragmentada de acuerdo a la fuente de energía que se tome en consideración: nuclear, petróleo y gas, carbón, energías renovables y biocombustibles, etc. (RAUSTIALA; VICTOR, 2004). En el plano internacional, y por fuera del sistema de la Organización de Naciones Unidas, ${ }^{6}$ se erigieron dos organizaciones: la Organización de los Países Exportadores de Petróleo (OPEP), nucleada en torno a grandes productores de petróleo, en 1960, y la Agencia Internacional de la Energía, circunscribiendo a los grandes consumidores de dicho recurso, en 1974. Finalizada la Guerra Fría, esas organizaciones crearon una nueva institución de diálogo que incluyera a ambas partes: el Foro Internacional de la Energía (IEF). Finalmente, cabe mencionar a la Agencia Internacional de la Energía Renovable (conocido como IRENA), fundada en 2011 gracias a la iniciativa alemana y a su liderazgo internacional en dicha área (DOWNIE, 2015).

Dejando de lado a la OPEP por su naturaleza restringida, las demás organizaciones mencionadas carecen de gran capacidad de influencia en el contexto energético internacional, a pesar de poseer una membresía de carácter universal. Sin embargo, es indiscutible que la Agencia Internacional de la Energía (IEA) ha mantenido un rol preponderante en la arquitectura energética

6 Es importante mencionar a dos organizaciones que forman parte de su espectro. Por un lado, el Consejo Mundial de la Energía (WEC, por sus siglas en inglés), establecido en 1923 y posteriormente incorporado como órgano de las Naciones Unidas. Por otro lado, y considerando las preocupaciones de la época, en 1957 se creó la Agencia Internacional de la Energía Atómica. 
mundial por el hecho de estar conformada por los miembros de la Organización para la Cooperación y el Desarrollo Económico (OCDE), es decir, por las potencias tradicionales.

La IEA, que nació como producto del primer shock petrolero, tenía fines explícitos de asegurar dicho recurso estratégico en términos razonables y equitativos y crear mecanismos para poder manejar las emergencias de suministro y evitar un nuevo impacto en sus economías. Con este objetivo se crearon las reservas estratégicas de petróleo que, ante una disrupción en el suministro mundial, debían asegurar el abastecimiento de un país entre 6090 días, según el caso. Con el pasar de los años, la IEA comenzó a ampliar el espectro de fuentes de energía, hasta abordar no sólo los hidrocarburos convencionales y no convencionales, sino también las fuentes de energía renovables. Por otro lado, dicha agencia es la única que mantiene mecanismos de diálogos con las demás organizaciones, es decir, IRENA, IEF, OPEP, G8 y G20, siendo identificada como focal en el dominio del área (FLORINI, 2011; VAN DE GRAAF, 2012).

Las modificaciones en la jerarquía internacional a partir del 2000, y particularmente la aparición de "nuevos jugadores energéticos globales", pusieron en cuestionamiento la legitimidad y representatividad de la IEA. Incluso, el hecho de que China no integrara la organización resultaba anacrónico. De todos modos, la institución comenzó a dar indicios hacia una ampliación desde el 2010, cuando su director ejecutivo, Nobou Tanaka, expresó: “Our relevance is under question because half of the energy consumption alreadyis in non-Organisation ofEconomic Cooperation and Development countries. And for oil it is soon coming that the majority of consumption is happening in non-OECD countries" (en Hoyos, 30/03/2010).

En ese momento, se extendió la invitación a China para sumarse como miembro. No obstante, el gobierno chino rechazó la invitación dado que la membresía implicaba, por un lado, pasar a integrar la OCDE y, por otro, la posesión de reservas estratégicas de petróleo equivalentes a 90 días. La primera condición iba en contra de su auto-reconocimiento como país en desarrollo, que ha 
sido el basamento histórico de la política exterior de la República Popular. En cuanto a la segunda condición, China se mantuvo reacia a transparentar la cantidad de reservas estratégicas acumuladas. Si bien es verdad que comenzó a participar en algunas de las actividades de la IEA a partir de 1997, fortaleciendo la recolección estadística de la organización, integrarla podría involucrar obligaciones y responsabilidades mayores a nivel internacional (KONG, 2011).

Interesa decir, además, que en la cumbre del G8 de 2006, en donde China participó como Estado invitado, el presidente Hu Jintao enfatizó la cooperación internacional como forma de resolver los problemas energéticos. Si bien fue la primera vez que un líder chino expresó tal afirmación, ello no significó un cambio inmediato en su política. A partir de 2010 en adelante, se produjo un debate entre académicos chinos que consideraban que su país debía tener una participación positiva en la cooperación energética global (HE, 2016, p. 8-9). La llegada de Xi Jinping al poder implicó cierto cambio hacia una política exterior más asertiva en todos los aspectos. Su visión de convertir a China en un país desarrollado para el 2020 (WANG, 2014) ha tenido cierto correlato en un mayor perfil internacional como es el caso de la gobernanza energética.

Por otra parte, a partir de 2013, se observaron actitudes más proclives a cooperar de forma multilateral en materia energética entre las potencias emergentes y las potencias tradicionales, derivando en la firma de un comunicado conjunto entre la IEA y seis países socios -Brasil, China, India, Indonesia, Rusia y Sudáfricacomo preludio de la iniciativa de asociación (DOWNIE, 2015). Lo antedicho vislumbra la voluntad de los miembros plenos de la IEA de crear una nueva categoría en 2015, los "miembros asociados", con el objeto de reflejar el rol creciente de los países no-OCDE en los flujos energéticos globales (NAKANO; SINGH, 2017). Finalmente, de dicha declaración de intenciones de 2013 se derivó la aceptación de China en calidad de miembro asociado en 2015, de India y Brasil en 2017 y de Sudáfrica en 2018, propiciando una relevante modificación en la gobernanza energética global. 
La inclusión de India en la organización tuvo un devenir muy similar al de China. Nueva Delhi también había comenzado a colaborar con información estadística a la IEA desde 1998, luego de la firma de una declaración de cooperación. No obstante, se mantuvo distante frente a la posibilidad de comprometer sus intereses en la agenda de la agencia. De hecho, mientras Manmohan Singh era Primer ministro, su gobierno recomendó que no debería convertirse en miembro per se. Se sugería continuar interactuando y colaborando, ya que permitía al país maximizar sus reservas de petróleo crudo y beneficiarse de la asistencia técnica de la organización, aunque evitando las obligaciones que supondría la membresía (DADWAL, 2017).

Sin embargo, el cambio de gobierno en India, en 2014, conllevó a la asunción de Narendra Modi y, con ello, la intención de proyectar aún más a Nueva Delhi a nivel internacional. Por esa razón, cuando el nuevo director ejecutivo de la IEA, Fatih Birol, afirmó: “We can't talk about the future of the global energy markets without talking with India" (en DADWAL, 2017), el gobierno indio no pudo negar su afiliación. Además, debemos contemplar que su rival asiática -China- ya se había convertido en miembro asociado, una excusa más para determinar su aceptación en marzo de 2017.

Finalmente, el caso de Brasil se sucedió en similares circunstancias, aunque con algunos matices. La cooperación con la IEA comenzó a partir de 1998 -a través de la participación del Ministerio de Minas e Energía del país en grupos de trabajo- y se intensificó a partir de 2006 al más alto nivel en las reuniones ministeriales de la agencia (Declaração Conjunta de Associação entre Brasil e AIE, 2017). Luego del impeachment que desplazó a la presidenta Dilma Rousseff en 2016, el gobierno de Temer ajustó su política exterior con dirección hacia las potencias tradicionales. En ese sentido, y considerando que Brasil pasó a destacarse como gran productor de petróleo a partir de 2014, Temer retrotrajo las políticas de explotación del recurso -aplicadas durante el gobierno de Lula Da Silva-, hacia otras con menor intervencionismo estatal. En decir, se flexibilizó el sistema de rondas de licitación de bloques 
para la concesión de actividades de exploración y producción, de manera similar al aplicado en la Lei do Petróleo de 1997. No es casual que el propio director ejecutivo de la IEA, en el discurso que brindó en la ceremonia de asociación de Brasil a la agencia, haya reconocido la importancia de este país por haberse convertido de importador a exportador de petróleo y por las reformas realizadas en el sector petrolero, que lo volvieron más atractivo a la inversión en escala (BIROL, 2017).

De lo anteriormente expuesto, queda demostrado que la incorporación de estos grandes jugadores energéticos globales le ha sumado legitimidad y mayor representatividad a la agencia. La inclusión de China, India y Brasil significó que la consideración de la totalidad de sus miembros (plenos y asociados) equivalga ahora al $70 \%$ del consumo de energía mundial. De la misma manera, la agencia se beneficia al ganar acceso a la información de estos países, principalmente China, y al sumar las reservas petroleras de estos estados en el caso de una disrupción en el suministro mundial.

El caso de Sudáfrica merece una mención en particular. Algunas posturas académicas (LIPTON, 2013; NOSSEL, 2016; SCHOEMAN, 2015) lo consideran un "emergente débil" debido a que sus capacidades materiales de poder no tienen parangón al compararlas con las demás potencias emergentes mencionadas. Al respecto, este país no figura entre los principales puestos de los flujos energéticos globales aquí analizados. No obstante, se debe reconocer que es concebida como la "puerta de entrada" a África Subsahariana, dado que posee capacidad de influencia relativa sobre su entorno regional próximo. En ese sentido, no es menor que en la ceremonia de asociación de este país a la IEA se haya resaltado que es "a major player in African energy markets representing the largest energy consumer on the continent".7 Es decir, su relevancia continúa ligada al rol de preponderancia que cumple en el continente africano.

\footnotetext{
7 Información extraída de https://www.iea.org/newsroom/news/2018/november/south-africa-joins-the-iea-family-boosting-global-energy-governance.html. Consultada el 16-03-2019.
} 
Ahora bien, ¿en qué se benefician las potencias emergentes aquí trabajadas al formar parte de la IEA como miembros asociados? Dicho estatus permite participar en las diferentes instancias de reunión de la agencia sin invitación previa. Asimismo, se benefician al acceder a un tratamiento prioritario en el acceso a la capacitación y entrenamiento provistos por la IEA. Para India, en particular, el acercamiento a la agencia podría promover el respaldo de las instituciones financieras para apoyar sus programas energéticos tales como el de energía solar. A nivel internacional, Narendra Modi lanzó, en 2015, la iniciativa 'Alianza Solar Internacional', proponiendo la firma del tratado en 2016. La propuesta le otorga una plataforma para posicionarse como líder de una nueva agenda ambiental y energética. El éxito de la Alianza Solar dependerá del número de países que se sumen, por lo cual una participación activa en diferentes foros multilaterales le brinda la oportunidad de visibilizarla.

En cuanto a Brasil, de acuerdo a la jefa de la División de Recursos Energéticos no renovables del Departamento de Energía del Ministerio de Relaciones Exteriores de ese país, Bárbara Bélkior, ${ }^{8}$ el hecho que Brasília sea parte de la organización le ofrece la posibilidad de modificar la concepción de seguridad energética, hacia un concepto ampliado. Dado que Brasil posee la matriz energética interna más diversificada de las potencias emergentes mencionadas en este trabajo, su gobierno pretende aportar la necesidad de alejarse de las dicotomías "alimento versus combustibles, autos eléctricos versus vehículos a motor de combustión o agua versus energía".

Para China, finalmente, pertenecer a la agencia le ha supuesto más concesiones que beneficios. Esto se debe a que su participación implicó transparentar la cantidad de reservas estratégicas de petróleo que posee en su territorio, un gran paso para un país que hasta hace apenas cinco años se mostraba reacio a dar a conocer dicha información.

8 Entrevista realizada en Brasilia en agosto de 2018 en el Ministerio de Relaciones Exteriores. 
Por otra parte, es importante destacar que China, India, Brasil y Sudáfrica se encuentran actualmente en proceso de adhesión a la OCDE, ${ }^{9}$ lo cual conllevaría, a su vez, cambios de categorías a miembros plenos de la IEA. Dicho proceso supondrá un período de adaptación hasta alcanzar la cantidad de reservas estratégicas de petróleo requeridas, siendo India uno de los países que mayor desfasaje presenta, al contar con una capacidad de tan sólo 13 días de aprovisionamiento de emergencia (NAKANO; SINGH, 2017).

La temática energética constituye entonces uno de los puntos más importantes de la actual agenda internacional. Esto se debe a que existe una interdependencia estrecha entre las cuestiones energéticas, el cambio climático y los modelos de desarrollo interno de los países. Al igual que en otros ámbitos de naturaleza restringida -como fue el caso del G7, que derivó en el establecimiento del G20- la IEA y la OCDE se encuentran atravesando un intenso debate referente a su legitimidad y capacidad para poder dar respuestas a los desafíos planteados. La inclusión de China primero, y luego India, Brasil y Sudáfrica no es menor, enmarcándose en una realidad internacional en transformación. Se manifiesta, además, un cambio actitudinal en China, antes autoexcluida de determinados ámbitos liderados por las potencias tradicionales. Si estas potencias emergentes podrán moldear las normas que guían la gobernanza global energética, aún es una pregunta abierta. Lo cierto es que estos países vienen aceptando las reglas de juego establecidas, reforzando el orden de hegemonía liberal.

\section{Las patentes farmacéuticas, como ámbito de cuestiona- miento al orden hegemónico noratlántico ${ }^{10}$}

Los derechos de propiedad intelectual -los cuales incluyen patentes, marcas, modelos y dibujos, entre otros- han constituido

\footnotetext{
9 Información extraída de OCDE, disponible en https://www.oecd.org/centrodemexico/paisesmiembros.htm. Consultado el 1503-2019.

10 Las negociaciones internacionales en materia de patentes farmacéuticas constituyen una línea de investigación desarrollada por Clarisa Giaccaglia en su calidad de investigadora del CONICET.
} 
tradicionalmente una temática de gran envergadura. Las cuestiones vinculadas particularmente a las patentes farmacéuticas ganaron un interés especial considerando los efectos que éstas tienen sobre los niveles de salud nacionales.

El sector farmacéutico se ha consolidado en los estados del Norte. Su desarrollo en las naciones del Sur, en cambio, ha sido exiguo con actividades en escasos países, entre los cuales sobresalen India o Brasil, que consiguieron expandir una industria farmacéutica propia. El caso de India es singularmente relevante puesto que ha desplegado una poderosa industria de medicamentos genéricos.

Si bien el tratamiento de los derechos de propiedad intelectual se había institucionalizado por medio de la creación de la Organización Mundial de la Propiedad Intelectual (OMPI) en 1967, la incorporación de este tema en las negociaciones desarrolladas, en el GATT y luego en la OMC, posicionaron esta temática como parte de la liberalización comercial internacional iniciada en los albores de la post-Guerra Fría.

Tanto el gobierno de India como el de Brasil mostraron resistencias frente a estas primeras negociaciones efectuadas en el GATT, puesto que hubieran preferido debatir estas cuestiones en el ámbito de la OMPI. Finalmente, la última Ronda del GATT permitió la elaboración del Acuerdo de los Derechos de Propiedad Intelectual relacionados con el Comercio (ADPIC o TRIPS) que entró en vigor el $1^{\circ}$ de enero de 1995.

Muchas de las discusiones suscitadas en dicho momento, entre las potencias tradicionales y las potencias emergentes, se originaron a raíz de que el Acuerdo de los ADPIC incluyó la protección de los derechos conferidos por una patente frente a usos por parte de terceros no autorizados. De esta manera, se incorporó el concepto de licencia obligatoria, que es el permiso que da un gobierno para fabricar un producto patentado sin la autorización del titular de la patente, a condición de que éste último sea informado y remunerado por la utilización de la misma (hoja informativa OMC, 2006, p. 4). Cabe aclarar que el término 
"licencias obligatorias" no figura en el Acuerdo sobre los ADPIC en relación a las patentes, sino que se refiere a "otros usos sin autorización del titular". De esta manera, en caso de "emergencia nacional" o de "otras circunstancias de extrema urgencia", no es necesario obtener una licencia voluntaria (hoja informativa OMC, 2006, p. 5).

En los años siguientes, algunas potencias emergentes -como India o Brasil- empezaron a emplear licencias obligatorias en relación a los productos farmacéuticos. Este uso generó malestar con las potencias tradicionales, quienes argumentaron que, de esta forma, se burlaban las leyes de derechos de propiedad intelectual. De igual manera, en los últimos años del siglo $X X$, un puñado de países en desarrollo junto con relevantes organizaciones de la sociedad civil se movilizaron a fin de obtener una renegociación de este acuerdo en lo concerniente a patentes farmacéuticas.

Es importante destacar que, a partir de la década del noventa, algunas potencias emergentes se vieron implicadas en una serie de disputas legales vinculadas a la aplicación de las patentes farmacéuticas, las cuales significaron antecedentes fundamentales para el ulterior desarrollo de las negociaciones en la OMC.

En el caso brasileño, como consecuencia de presiones ejercidas desde el gobierno norteamericano, el país latinoamericano aprobó, en 1996, la ley 9.279 de Propiedad Industrial en virtud de la cual se reconocieron las patentes farmacéuticas (MELLO e SOUZA, 2011, p. 10). No obstante, todos aquellos productos que habían sido comercializados en cualquier lugar del mundo antes del 14 de mayo de 1997 -fecha en la que entró en vigor la nueva ley- se tornaron para siempre inelegibles para su patentamiento en Brasil. Por consiguiente, "diez medicamentos antirretrovirales permanecieron sin protección de patentes en el país, pudiendo ser legalmente reproducidos" (ORSI et al. en Mello e Souza, 2011, p. 10).

En este contexto, el Instituto de Tecnologia em Fármacos, unidad científico tecnológica de Fiocruz- dependiente del Ministerio Nacional de Salud- comenzó a fabricar versiones genéricas de medicamentos antirretrovirales. A partir del empleo de técnicas de 
ingeniería inversa, dicha entidad descubrió la fórmula de la mayor parte de estos antirretrovirales no patentados en suelo brasileño y comenzó a producirlos utilizando principios activos importados principalmente de India y China. De este modo, el Ministerio de Salud pudo sustituir la importación de antirretrovirales caros por equivalentes fabricados en Brasil, lo cual implicó una disminución de los precios de estos medicamentos de un $81 \%$ en el 2001 (MELLO e SOUZA, 2011, p. 9-10).

Años más tarde, en 1999, el gobierno de Fernando Henrique Cardoso aprobó una nueva legislación que permitía a empresas nacionales la fabricación de productos patentados por medio de licencias obligatorias, en casos de emergencia pública (Ley de Genéricos de 1999).

La nueva legislación de Brasilinquietó a los países desarrollados, en especial a Estados Unidos, donde la Asociación de la Industria Farmacéutica (PhRMA) operaba en contra de la normativa brasileña desde hacía varios años. Estos resquemores se cristalizaron en el 2000, cuando el gobierno estadounidense ingresó una solicitud de consulta ante el órgano de solución de diferencias de la OMC con respecto a la ley de patentes brasileña (diferencia WT/DS199/1, 2000). Más precisamente, la administración norteamericana cuestionó el requisito de "explotación local", según el cual una patente será objeto de licencia obligatoria si la materia de la patente no se "explota" en territorio brasileño. Los representantes de Estados Unidos intentaron encuadrar el proceso negociador en términos de comercio internacional, mientras que Brasil buscó enmarcar el asunto como una cuestión de salud pública y de derechos humanos. Finalmente, Estados Unidos retiró en 2001 su reclamo y el conflicto se resolvió mediante una solución mutuamente convenida, que más tarde fue informada a la OMC (diferencia WT/DS199/4, 2001).

Varios motivos explican esta solución. Desde el lado norteamericano, en primer lugar, se privilegió la necesidad de evitar crear jurisprudencia (en caso de que el panel de la OMC decidiese a favor de Brasil) estableciendo un precedente para muchos otros 
países en desarrollo. En segundo lugar, el desenlace fue también el resultado de la presión desplegada por la prensa internacional y por las organizaciones civiles internacionales ya mencionadas, que apoyaron decididamente al gobierno de Brasil.

Con respecto al caso sudafricano, un hecho de relevancia ocurrió en 1997 cuando el gobierno autorizó, por medio de una enmienda a la ley farmacéutica nacional, el uso de importaciones paralelas y la producción de medicamentos contra el HIV por parte de empresas sudafricanas bajo licencias obligatorias, a fin de reducir los costos de los tratamientos (The Medicines and Related Substances Control Act, Act $N^{\circ}$ 90). Las importaciones paralelas son aquellas realizadas con productos elaborados legalmente en el extranjero e importados sin el consentimiento del titular de la patente (Informe de la OMPI, 2000, p. 100).

Ante esta situación, la Asociación de Fabricantes Farmacéuticos de Sudáfrica -con el respaldo de 39 multinacionales farmacéuticas-, inició en 1999 una demanda judicial contra el gobierno sudafricano. El Congreso de Estados Unidos, por su parte, amenazó con interrumpir toda la ayuda al desarrollo destinada a ese país. El gobierno sudafricano, en tanto, advirtió que el Acuerdo sobre los ADPIC consentía, de forma expresa, el empleo de las licencias obligatorias y las importaciones paralelas. No obstante, el gobierno de Estados Unidos presionaba enérgicamente para que esta enmienda fuese derogada. Meses más tarde, no obstante, los dos gobiernos lograron llegar a un acuerdo. Entre las razones que condicionaron el cambio de postura del gobierno norteamericano se encuentra el mayor conocimiento mediático del tema. Las compañías farmacéuticas retiraron la demanda judicial con serios perjuicios para su imagen internacional. El gobierno de Sudáfrica sólo se comprometió a adecuar sus acciones a lo que se decidiera en el marco de las negociaciones de la OMC.

Los acontecimientos ocurridos en Brasil y Sudáfrica fueron antecedentes cruciales para que a fines de 2001 este tema fuese tratado en la OMC. Efectivamente, en la Cuarta Conferencia Ministerial, efectuada en Doha en noviembre de 2001, se realizó 
la firma de la Declaración relativa al Acuerdo sobre los ADPIC y la Salud Pública -también conocida como Declaración Doha-, que implicó un verdadero éxito para los países del Sur, encabezados por las potencias emergentes.

Desde un principio, India y Brasil se mostraron unidos en una misma posición negociadora. Frente a eso, la delegación de Estados Unidos intentó cooptar al Grupo Africano con el objeto de debilitar la postura de las potencias emergentes. Los representantes norteamericanos propusieron, para los Países Menos Adelantados (PMA), una extensión del período de transición para el cumplimiento del Acuerdo de los ADPIC, en lo relativo a productos farmacéuticos. No obstante, ese grupo desestimó la propuesta y los estados del Sur pudieron sostenerse como un bloque cohesionado a través de una coalición que incluyó a 80 países.

La Declaración de Doha constituyó un valioso progreso sobre dos cuestiones que habían quedado ambiguas en el acuerdo de 1995: las licencias obligatorias y la estipulación de emergencias nacionales. Con respecto al primer tema, la declaración determinó que "cada miembro tiene el derecho de conceder licencias obligatorias y la libertad de determinar las bases sobre las cuales se conceden tales licencias" (Declaración de Doha, OMC, 2001, art. 5.b). En relación al segundo tema, el acuerdo sostiene que "cada miembro tiene el derecho de determinar lo que constituye una emergencia nacional u otras circunstancias de extrema urgencia, quedando entendido que las crisis de salud pública, incluidas las relacionadas con el $\mathrm{HIV} /$ sida, la tuberculosis, el paludismo y otras epidemias, pueden representar una emergencia nacional [...]" (art. 5.c). Finalmente, la declaración extendió el plazo que el acuerdo había acordado para su puesta en vigor en los PMA. La fecha original de julio de 2013 se pospuso hasta el $1^{\circ}$ de enero de 2016 (art. 7).

Sin embargo, algunas cuestiones permanecieron pendientes. El artículo 31 del Acuerdo establecía que los productos fabricados al amparo de licencias obligatorias "se usarán principalmente para abastecer el mercado interno". Es decir, se podían exportar medicamentos fabricados bajo licencia obligatoria únicamente si 
la parte "predominante" de la producción circulaba en el mercado interno. Por tanto, restaba encontrar una solución para los países que carecían de un sector farmacéutico o cuyo desarrollo era aún incipiente. En ese caso, la normativa podría afectarlos al no permitirles importar la cantidad de medicamentos genéricos necesarios para cubrir la totalidad de sus necesidades nacionales.

Esa demanda se subsanó en agosto de 2003 al acordarse que "cualquier país miembro puede exportar productos farmacéuticos genéricos fabricados al amparo de licencias obligatorias para atender las necesidades de los países importadores", dejando de lado las restricciones en las cantidades" (Hoja informativa de la OMC, 2006, p. 6).

La Declaración de Doha significó una trascendental victoria para las potencias emergentes que lograron actuar como un solo bloque en la defensa de sus posiciones. Las potencias tradicionales quisieron evitar un quiebre en el proceso negociador a fin de obtener la apertura de una nueva ronda de negociaciones comerciales. Por último, las organizaciones civiles internacionales actuaron eficazmente al conseguir el interés de la prensa internacional (BARTSCH; KOHLMORGEN, 2007, p. 17).

En función de los logros obtenidos internacionalmente, el gobierno de Lula da Silva introdujo, en 2003, una modificación a la legislación nacional brasileña por la cual se permite la importación de genéricos producidos bajo licencias obligatorias, siempre que la producción doméstica se muestre inviable (MELLO e SOUZA, 2011, p. 14). Los cambios en la normativa internacional también repercutieron al interior de Sudáfrica, que a partir de 2004 inició la distribución gratuita de antirretrovirales por parte del sistema de salud público, esto es, versiones genéricas fabricadas por firmas locales.

Resulta importante aclarar que las exenciones establecidas, por la enmienda realizada al Acuerdo sobre los ADPIC en 2003, eran provisionales. Las constantes y sucesivas apelaciones realizadas por las potencias emergentes -especialmente por medio de la coalición IBSA- fueron cruciales para la transformación de los 
consensos alcanzados en una enmienda permanente del Acuerdo sobre los ADPIC, cometido que se logró en el 2005.

Nuevos episodios vinculados a la política interna de algunos poderes emergentes adquirieron relevancia internacional en 2007, generando impactos en las discusiones globales en materia de salud y propiedad intelectual. El gobierno brasileño emitió su primera licencia obligatoria para el antirretroviral efavirenz, patentado por la empresa farmacéutica alemana Merck. En consecuencia, el medicamento comenzó a ser importado de India (MELLO e SOUZA, 2011, p. 16-17). La decisión del gobierno brasileño supuso que este país se convirtiera en el primero de América Latina en suspender legalmente la patente de un medicamento contra el HIV por "interés público".

De forma similar a lo ocurrido en los sucesos descriptos con anterioridad, mientras quelas organizacionescivilesinternacionales dedicadas a problemas sanitarios aplaudieron la medida brasileña, remarcando tanto su legalidad como su legitimidad, las potencias tradicionales consideraron que esa disposición era innecesaria y amenazaron con reducir sus inversiones en el país (MELLO e SOUZA, 2011, p. 17).

Por otra parte, también en 2007, el gigante farmacéutico Novartis realizó una demanda judicial contra India a raíz de que el gobierno nacional se negó a reconocer la patente de "gleevec", un medicamento empleado para casos de leucemia. En efecto, la ley de patentes de India de 1970 es reconocida mundialmente, pues anuló las patentes sobre productos y sólo permitió patentes de procesos. A raíz de ello, las compañías indias pueden fabricar variantes más baratas de una droga, patentada en el extranjero, comercializando el mismo producto siempre y cuando sea elaborado a partir de un proceso diferente. Esa legislación propició la generación de una capacidad tecnológica nacional con precios accesibles. De esa manera, la industria farmacéutica india se convirtió en una de las más prósperas del mundo, con una fuerte presencia en los mercados de exportación (CHATURVEDI, 2011, p. 7). 
En 2004, el gobierno indio aprobó una enmienda a su ley de patentes para adecuarse a los requerimientos exigidos por la OMC. No obstante, incluyó un amparo decisivo, en base a la denominada Declaración de Doha, por la cual sólo se reconocen "patentes de medicamentos auténticamente nuevos". En otros términos, patentes que sean producto de investigaciones innovadoras. Además, India se reservó el derecho de estipular si un medicamento es o no auténticamente nuevo. En el caso de gleevec, se alegó que los activos del remedio sólo eran "nuevas formas de componentes ya conocidos", por lo cual Novartis no tenía derecho sobre ellos. El tribunal de Madrás falló finalmente en favor del gobierno indio, contemplando su derecho a producir medicamentos genéricos contra enfermedades mortales como el cáncer o el sida, a precios razonables (SOUSA, 2008, p. 177).

La incautación de medicamentos genéricos por presunta falsificación constituyó un nuevo capítulo en las disputas entre las potencias tradicionales y las potencias emergentes. El litigio comenzó en 2008, cuando las autoridades aduaneras holandesas embargaron, en el Aeropuerto Schiphol de Amsterdam, un cargamento de 500 kgs de losartán potásico (medicina para la tensión arterial) que el laboratorio indio Dr. Reddy's estaba enviando a Brasil. El cargamento se retuvo por pedido de la empresa norteamericana Merck Sharp \& Dohme -titular de la patente de este medicamento en Holanda- bajo la sospecha de que se trataba de una falsificación. Sin embargo, y en vista de que losartan no está patentado ni en Brasil ni en India, la transacción no podía infringir los derechos de propiedad intelectual en el mercado europeo por tratarse de una mercadería "en tránsito". En consecuencia, el cargamento fue devuelto a su propietario quien, finalmente, decidió despacharlo de vuelta a India.

Conforme se fueron repitiendo ese tipo de situaciones, puesto que el gobierno indio llevaba registro de otras 19 retenciones de medicamentos en tránsito, en mayo de 2010, los gobiernos de India y Brasil denunciaron a Estados Unidos y a la Unión Europea ante la OMC por obstaculizar asiduamente el transporte de 
medicamentos genéricos alegando infracciones a los derechos de patente (BBC Mundo, 12/05/2010).

A partir de la segunda década del siglo XXI, varias potencias tradicionales han participado en acuerdos bilaterales para adoptar un estándar de protección más alto, dinámica que se ha dado a conocer como "TRIPS-Plus". En ese sentido debe entenderse la propuesta en 2006 de Estados Unidos, Europa y Japón para la firma del Acuerdo Comercial Anti-falsificación (ACTA). Desde la perspectiva de sus propulsores, dicho acuerdo buscaba aumentar los procedimientos de protección de los derechos de propiedad intelectual con el objeto de reducir la propagación de productos falsificados. Biswajit Dhar y Reji Joseph (2010, p. 21-22) advierten que la normativa planteada por el ACTA no distingue claramente entre "medicamentos genéricos autorizados" y "medicamentos falsificados". Bajo el pretexto de la lucha contra la falsificación, la propuesta podría conllevar serias implicancias para el comercio internacional de medicamentos genéricos.

Otra de las acciones insertas en esta lógica se vincula a la firma de acuerdos de libre comercio entre las potencias tradicionales y los países en desarrollo, en los cuales las primeras incorporan, dentro de las disposiciones, normas TRIPS-Plus. Los ejemplos más comunes de disposiciones TRIPS-Plus incluyen "prolongar la duración de la patente más allá del mínimo de 20 años del Acuerdo sobre los ADPIC, someter la expedición de licencias obligatorias a fórmulas que el Acuerdo no exige, y restringir las excepciones que facilitan la introducción rápida de medicamentos genéricos" A modo de ejemplo, cabe considerar los tratados de libre comercio de Estados Unidos firmados con Chile, Perú y Colombia, que contienen normas TRIPS-Plus a favor de empresas farmacéuticas extranjeras (ALLARD SOTO, 2015, p. 15-16). Dichas iniciativas han contado con un fuerte rechazo por parte de potencias emergentes como India, Brasil y Sudáfrica.

En cuanto a China, en 2012 se ha sumado al posicionamiento del resto de los emergentes. En efecto, se llevaron adelante revisiones de las leyes nacionales de protección intelectual, 
las cuales permiten al gobierno de Beijing conceder licencias obligatorias a ciertas empresas para que fabriquen versiones genéricas de fármacos patentados para situaciones de emergencia pública. Del mismo modo, esas compañías podrán solicitar permiso para exportar dichos productos a otros países (Reuters, 08/06/2012). Es importante considerar además que, de acuerdo a algunas estimaciones, China se convirtió, en 2017, en el segundo consumidor global de medicinas.

En suma, el conflicto entre potencias tradicionales y emergentes se ha sostenido y recrudecido durante los últimos 30 años, incluyendo una multiplicidad de estrategias por parte de ambos grupos a fin de imponer sus criterios e intereses en materia de patentes farmacéuticas en el ámbito global.

\section{Conclusiones}

Luego de haber abordado el rol de las potencias emergentes en dos áreas temáticas de la agenda internacional contemporánea, energía y patentes farmacéuticas, es posible apreciar hasta qué punto se ha producido una cierta transformación de los espacios de negociación multilateral aquí trabajados.

De acuerdo a lo expuesto en el primer ámbito de análisis, se refuerza la primera parte de la hipótesis de trabajo. Es decir, que las potencias emergentes han intentado llegar a acuerdos con las potencias tradicionales, aceptando ideas dominantes de la tradicional estructura de poder global, de hegemonía noratlántica. La aceptación de China, India, Brasil y Sudáfrica a formar parte de la Agencia Internacional de la Energía, y que a su vez dichos países se encuentren en proceso de admisión a la OCDE, es un signo claro de transición hacia una gobernanza energética global que intenta ser representativa de los cambios ocurridos en el mercado energético mundial en las últimas dos décadas. En otras palabras, las potencias tradicionales han cedido cierto espacio de actuación 
a estos países, al reconocerlos como cruciales para asegurar la estabilidad en los flujos energéticos y "su apoyo" ante una eventual crisis energética que afecte al mundo en su conjunto.

Sin embargo, la creación de la categoría de "miembro asociado" a la Agencia no implica una redistribución de las cuotas de poder, dado que se lo puede considerar como un momento intermedio, de adaptación, hasta que efectivamente cumplan con los requisitos que implica ser miembros plenos. Principalmente, reunir la cantidad de reservas estratégicas de petróleo equivalentes a 90 días de aprovisionamiento interno, y ello dependerá de la voluntad política de cada potencia emergente y de su capacidad material real para poder alcanzarlo. En términos comparados, China y Brasil se encuentran mucho más cercanas a cumplir con el objetivo que India y Sudáfrica. El primero por su protagonismo y avance creciente en el mercado petrolero mundial y el segundo, por la explotación de las reservas del pre-sal. India también ha extendido su actuación e influencia en los países productores de petróleo, pero depende de las importaciones en un $80 \%$, volviéndola altamente vulnerable ante un shock externo.

En cuanto al ámbito de negociación de las patentes farmacéuticas, el análisis aquí realizado refuerza la segunda parte de la presunción inicial, es decir, que las potencias emergentes han tendido a resistir y/o propiciar cambios en los esquemas decisorios vigentes frente a normativas desfavorables, con el objeto de reforzar sus cuotas de poder mundial procurando reglas de juego que puedan generarles beneficios. En ese sentido, es interesante destacar que las decisiones de política doméstica predeterminaron la coalición entre las potencias emergentes en el ámbito de la OMC, defendiendo la necesidad de un accionar mancomunado frente a una temática de importancia fundamental para el bienestar de sus poblaciones.

En ese caso, el rol de liderazgo en conjunto entre India y Brasil, apoyados por Sudáfrica y por el espectro de los países en desarrollo, condujo a un logro histórico en la defensa de la producción de medicamentos esenciales. Las potencias emergentes arremetieron 
contra las normativas establecidas para democratizar a su favor un tópico de alto impacto en los índices de desarrollo humano. Las potencias tradicionales, por su parte, vienen resistiendo esas incursiones, desplegando una gama de estrategias que incluyen la suscripción de nuevos tratados más restrictivos, como el ACTA, así como la imposición de ciertas cláusulas en acuerdos bilaterales con países en desarrollo, a fin de concretar un estándar de protección más alto, que les posibilite mantener un status privilegiado en materia de patentes. En cuanto a China, su incipiente participación en este tipo de negociaciones abre más interrogantes que respuestas en cuanto a su futuro posicionamiento en este tema, convirtiéndola en un tema de seguimiento ineludible desde el ámbito académico.

En función de los dos temas estudiados, se puede apreciar que tanto Estados Unidos como Europa se resienten y repliegan en determinados temas de la agenda global, o bien promueven la inclusión y apertura de otras áreas, siempre con el mismo fin: preservar su status quo o estándar internacional alcanzado. De esa forma, promovieron acciones cooperativas inclusivas en la IEA con el objeto de que sus reglas abarquen a las potencias emergentes. No obstante, batallan contra éstos últimos en el ámbito de las patentes farmacéuticas, ya que podrían poner en jaque un sector productivo altamente rentable, que conllevaría pérdidas macroeconómicas internas.

En definitiva, las potencias tradicionales continúan esforzándose por mantener el orden internacional liberal, de hegemonía noratlántica, ylas potencias emergentes vienen actuando, en algunos ámbitos, como reforzadoras y en otros como cuestionadoras de dicho ordenamiento. De todas maneras, su rol de cuestionadoras no lo ejercen contra los regímenes internacionales en sí, sino contra cómo dichas reglas establecidas afectan sus propios márgenes de maniobra. Las modificaciones pretendidas responden a un "revisionismo oportunista" de los espacios de negociación multilaterales producto de la Pax Americana, la cual en apariencia es cuestionada, pero una mirada más profunda demuestra que se 
Las potencias emergentes en los espacios multilaterales de negociación...

Clarisa Giaccaglia • María Noel Dussort

trata de una dinámica que aún nadie, ni siquiera los emergentes, quieren o están en condiciones de dejar caer.

\section{Referencias}

ABDenUR, Adriana Erthal. Can the BRICS Cooperate in International Security? International Organisations Research Journal, v. 12, N. 3, p. 73-93, 2017.

ALLARD SOTO, Raúl. Medicamentos esenciales y Acuerdo sobre los ADPIC: COLISIÓN ENTRE EL DERECHO A LA SALUD Y EL DERECHO DE PROPIEDAD INtelectual. Revista Salud Colectiva, v. 11, N. 1, 2015.

Allison, Graham. Destined for War: can America and China escape Thucydides's trap? New York: Mariner Books, 2017.

ARMijO, Leslie Elliott; ROBertS, Cynthia. The emerging powers and Global Governance: Why the BRICS matter. En: LOONEY, Robert (ed.).

Handbook of emerging eConomies. NeW York: Routledge, 2014.

AYLLÓN PINO, BRuno. Agentes tRansformadores de LA COOPERACIÓN PARA EL DESARROLLO: PODERES EMERGENTES Y COOPERACIÓN SUR - Sur. Relaciones INTERNACIONALES, v. 20, N. 40, P. 99-119, 2011.

BARTSCH, Sonja; KOHLMORGEN, Lars. The Role of SOUthern actors in GLOBAL GOVERnANCE: the fight Against HIV/AIDS. German Institute of Global and Area Studies (GigA), working paper n. 46, 2007.

BASSO, Larissa; VIOLA, Eduardo. Chinese energy policy progress and CHALLENGES IN THE TRANSITION TO LOW CARBON DEVELOPMENT, 2006-2013.

Revista Brasileira de Política Internacional (RBPI), v. 57, p. 174-192, 2014.

BIROL, Fatih. Discurso do Diretor-Executivo da Agencia Internacional de Energia (AIE), NA CERIMÔNIA dE ASSOCIAÇÃo do BRASIL À AgENCIA INTERNACIONAL de Energia (Versão em português). Brasília, 31 de outubro de 2017. 
BBC MUNDO. BRASIL E INDIA DENUNCIAN A LA UE POR INCAUTAR GENÉRICOS. BBC Mundo, 12 maYo 2010. DisPoniBLE EN: HTTP://WWW.BBC.CO.UK/MUNDO/ ECONOMIA/2010/05/100512_GENERICOS_OMC_LR.SHTML?PRI. CONSULTADO EL SEPTIEMBRE DE 2011.

BRASil. Presidência da República. Casa Civil. Subchefia para Assuntos Jurídicos. Lei N. 9.787, de 10 de feVereiro de 1999. Altera a LeI N. 6.360, DE 23 de SETEMBRO DE 1976, QUE DISPÕE SOBRE A VIGILÂNCIA SANITÁRIA, ESTABELECE O MEDICAMENTO GENÉRICO, DISPÕE SOBRE A UTILIZAÇÃO DE NOMES GENÉRICOS EM PRODUTOS FARMACÊUTICOS E DÁ OUTRAS PROVIDÊNCIAS. DISPONIBLE EN: HTTP://WWW. PLANAlto.GoV.Br/CCIVIL_03/LEIS/L9787.htM. Consultado EL 16 dE MARZO DE 2019.

Brautigam, Deborah. The dragon's gift: the real story of China in Africa. LONDON: OXFORD UnIVERSITY PRESS, 2010.

Bueno Rubial, María del Pilar. El acuerdo de París: ¿Una nueva idea SOBRE LA ARQUITECTURA CLIMÁTICA INTERNACIONAL? ReLACIONES INTERNACIONALES, N. 33, P. 75-95, 2017.

BuZAN, Barry; COX, Michael. China and the US: comparable cases of 'Peaceful rise'? The Chinese Journal of International Politics, v. 6, n. 2, P. 109-132, 2013.

CHATURVEDI, SACHIN. INDIA'S DEVELOPMENT PARTNERSHIP: KEY POLICY SHIFTS and institutional evolution. Cambridge Review of International Affairs, v. 25, N. 4, P. 557-577, 2012. DOI: 10.1080/09557571.2012.744639

Chaturvedi, Sachin. South-South Cooperation in Health and Pharmaceuticals: emerging trends in India-Brazil collaborations. RIS, DISCUSSION PAPER N ${ }^{0} 172,2011$.

ChATURVEDI, Sachin; SAHA, Sabyasachi. Competing imperatives of global GOVERNANCE AND NATIONAL INTERESTS WITHIN BRICS: AN INDIAN PERSPECTIVE.

Observer Research Foundation, occasional paper n. 136, 2017. 
Las potencias emergentes en los espacios multilaterales de negociación...

COOPer, Andrew F. Squeezed or revitalised? Middle powers, the G20 and the eVolution of global governance. Third World Quarterly, v. 34, N. 6, P. 963-984, 2013.

COSTA VAZ, Alcides (Ed.). Intermediate status, Regional LeAdership AND security: India, Brazil and South Africa. Brasília: Universidad de Brasilia, 2006.

DADWAL, Shebonti Ray. Why has India chosen to become a member of the International Energy Agency. Institute for Defence Studies and Analyses, 2017.

DHAR, BisWAJIT; JOSEPH, RejI. ANTI-COUNTERFEITING INICIATIVES AND tRADE IN generic medicines. Poverty in Focus, What can IBSA offer to the global community? Acadmic Forum IBSA, International Policy Centre for Inclusive GROWTH (IPC-IG).

DIFERENCIA WT/DS199/1 (2000). Solución DE DIFERENCIAS OMC. Solicitud de CELEBRACIÓN DE CONSUltas PRESENTADA POR Estados Unidos EN

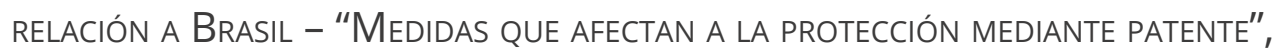
8 DE JUNIO DE 2000.

\section{DIFERENCIA WT/DS199/4 (2001). SoluCIón de DIFERENCIAS OMC.}

NotifiCACIÓN DE LA SOLUCIÓN MUTUAMENTE CONVENIDA ENTRE EL GOBIERNO DE Estados Unidos y el gobierno de Brasil, 5 de JULIO de 2001.

DOWNiE, Christian. Global energy governance: do the BRICS have the energy to drive Reform? International Affairs, v. 91, N. 4, p. 799-812, 2015.

DReZner, Daniel. El nuevo orden mundial nuevo. Foreign Affairs: LATINOAMÉRICA, v. 7, N. 3, P. 153-163, 2007.

DREZNER, DANIEL. The SYSTEM WORKED: GLOBAL ECONOMIC GOVERNANCE DURING the Great Recession. World Politics, v. 66, N. 1, P. 123-164, 2014. 
Las potencias emergentes en los espacios multilaterales de negociación...

DUSSORT, María Noel. Los modelos de vinculación externa en materia DE SEGURIDAD ENERGÉTICA IMPLEMENTADOS POR LAS POTENCIAS EMERGENTES. LOS casos de Brasil, India y China en África Subsahariana durante el período 2003-2014. 2019. Tesis (Doctorado en Relaciones Internacionales) Universidad Nacional de Rosario, Rosario, 2019.

DUSSORT, María Noel. Un abordaje de los intereses eConómicoCOMERCIALES EN LA POLÍtICA AFRICANA DE LOS GOBIERNOS DE LULA y DILMA: ¿IMPULSO PRESIDENCIAL CON APOYO PRIVADO O ESTRATEGIA PRIVADA BAJO EL Paraguas de LA DiplomaCia PResidencial? Monções, v. 5, N. 10, P. 10-38, 2016.

ENERDATA, DISPONIBLE EN: HTTPS://WWW.ENERDATA.NET/.

FLEMES, Daniel. EMERGING MIDDlE POWERS' SOFT BALANCING STRATEGY: STATE and perspectives of the IBSA dialogue forum. German Institute of Global And Area Studies (GIGA), N. 57, P. 1-30, 2007.

Florini, Ann. The International Energy Agency in Global Energy Governance. Global Policy, v. 2, Special Issue, p. 40-50, 2011. G20 Energy Efficiency Action Plan. Voluntary collaboration on energy efFiciency. Australia, 16 de nOViembre de 2014. Disponible en: htTPS:// WWW.MOFA.GO.JP/FILES/000059862.PDF. CONSULTADO EL 11 DE MARZO DE 2019.

GIACCAGLIA, Clarisa. ¿Muros O PUENTES?: LAS POTENCIAS tRADICIONALES y emergentes en un mundo convulsionado, Revista de Relaciones INTERNACIONALES DE LA UNAM, N. 131, P. 13-36, 2018. GiacCaGlia, Clarisa. Estrategias de política exterior de los poderes medios emergentes en la post-Guerra Fría. El CASO de IBSA - India, Brasil y SudÁfrica (2003-2010). 2012. Tesis (Doctorado en Relaciones INTERNACIONALES) - Universidad NaCIONAL de Rosario, Rosario, 2012. 
Las potencias emergentes en los espacios multilaterales de negociación...

GiaCCAGliA, Clarisa. Poderes tradicionales, emergentes y Re-emergentes: RELACIONES AMBiguas PERO PRAgMÁticas. Foro Internacional, v. LVII, N. 2, P. 422-459, 2017.

HE, Alex. China and global energy governance under the g20 framework. CIGI PAPERS, CANDÁ, N. 98, P. 1-16, 2016.

HoJA INFORMATIVA DE LA WEB OFICIAL DE LA OMC. LOS APDIC Y LAS PATENTES DE PRODUCTOS FARMACÉUTICOS. 2006. DISPONIBLE EN: HTTP://WWW.PPL.NL/ Bibliographies/WTo/files/6078.pdF. Consultado el 14 de MARzo de 2019. HOLBRAAD, Carsten. Las POtencias medias en la política internacional. MÉxıICO: F.C.E., 1989.

hOPEWELL, Kristen. Breaking the WTO: hoW emerging POWers DisRupted the neoliberal project. Stanford: Stanford University Press, 2016.

hOYOS, Carola. China InVITED to joIn IEA as OIL DEMAND Shifts.

Financial Times, 30 marzo 2010. Disponible en: htTPS://wWW.ft.com/ COnTEnt/0f973936-3вeb-11 dF-9412-00144fFeabdC0. Consultado el 16 de MARZO DE 2019.

HURRELL, Andrew. NarRatives of emergence: Rising POWERS AND the END of the Third World? Brazilian Journal of Political Economy, v. 33, n. 2, P. 203-221, 2013.

HURRELL, Andrew; Sengupta, Sandeep. Emerging powers, North-South relations and global climate politics. International Affairs, v. 88, n. 3, p. 463-484, 2012.

IAN, Chong Ja. Testing alternative Responses to poWer preponderance: BUFFERING, BINDING, BONDING AND BELEAGUERING IN THE REAL WORLD. INSTITUTE OF Defence and Strategic Studies, N. 60, 2004.

IKENBERRY, GILFORD JOHN. The FUtURE OF THE LIBERAL WORLD ORDER: internationalism after America. Foreign Affairs, v. 30, N. 3, 2011. INFORME DE LA OMPI. PATENT PROTECTION AND ACCESS tO HIV/AIDS Pharmaceuticals in Sub-Saharan Africa. 2000. Disponible en: http://www. 
Las potencias emergentes en los espacios multilaterales de negociación...

WIPO.INT/ABOUTIP/EN/STUDIES/PDF/IIPI_HIV.PDF. CONSULTADO EN SEPTIEMBRE DE 2011.

IEA - INTERNATIONAL ENERGY AGENCY. India Energy OUtLook.

World Energy Outlook Special Report. Paris, 2015.

IEA - INTERNATIONAL ENERGY AGENCY. World Energy Outlook 2007. ChINA AND INDIA INSIGHTS. PARIS, 2007.

IEA - INTERNATIONAL ENERGY AGENCY. World Energy Outlook 2010. PARIS, 2010.

IEA - INTERNATIONAL ENERGY AGENCY. World Energy Outlook 2013. PARIS, 2013.

IEA - INTERNATIONAL ENERGY AGENCY. World Energy Outlook 2016. PARIS, 2016.

IEA - INTERNATIONAL ENERGY AGENCY. World Energy Outlook 2018. PARIS, 2018.

KABUndA BADI, Mbuyı. África en la globalización neoliberal: Las alternativas africanas. Revista Theomai/Theomai Journal, N. 17, P. 77-87, 2008.

KONG, Bo. Governing China's energy in the context of Global governance. Global Policy, special issue, v. 2, N. S1, P. 51-65, 2011.

KRASNER, Sthephen (Ed.). International Regimes. London: Cornell UNIVERSITY PRESS, 1983.

LECHINI, GLAdYS. La COOPERACIÓN DE LOS EMERGENTES EN EL MUNDO EN desarrollo. En: PElFini, Alejandro; FUlQuet, Gastón (CoOrd.). Los BRICS EN LA CONSTRUCCIÓN DE LA MULTIPOLARIDAD: ¿REFORMA O ADAPTACIÓN?. Buenos Aires: CLACSO, 2015.

Lipton, David. South Africa: Facing the challenges of the global eConomy. International Monetary Fund online, 8 mayo 2013. 
MARTíN-MORENO, José María. The RISE OF EMERgING MARKETS AND ITS IMPACt. Modern Economy, N. 5, P. 967-979, 2014.

MEARSHEIMER, John J. The tragedy of great power politics. NeW York: W.W. NORTON \& COMPANY, 2001.

MEARSHEIMER, John J.; WALT, Stephen M. The CASE FOR OfFSHORE balancing. A superior U.S. grand strategy. Foreign Affairs, v. 95, N. 4, p. 70-83, 2016.

MELLO E SOUZA, André. O acordo sobre os Aspectos dos diretos de PROPRIEDADE INTELECTUAL RELACIONADOS AO COMÉRCIO (TRIPS): IMPLICAÇÕES E Possibilidades para a Saúde Pública no Brasil. Rıo de JaneIRO: INSTITUto de Pesquisa Econômica Aplicada (IPEA), 2011.

MILANI, CARLos. Los Países EMERGENTES en EL ORDEN MUNDIAL ACTUAL: Cambios y legitimidad política. En: PELFinI, Alejandro; FULQUET, Gastón (COORD.). Los BRICS EN LA CONSTRUCCIÓN DE LA MULTIPOLARIDAD: ¿REFORMA o AdAPtACIÓn? Buenos Aires: CLACSO, 2015.

MORASSO, Carla. Los aportes de la cooperación Sur-Sur a la agricultura: la presencia de China, Brasil e India en África Subsahariana. En: LeCHINI, Gladys; GiACCAGliA, Clarisa (Eds.). Poderes emergentes y COOPERACIÓn SUR-SUR. ROSARIO: UNR EdITORA, 2016.

NAKANO, Jane; SinGH, Kartikeya. India joins International Energy Agency as an Association country. Center for strategic \& international studies, 2017. DISPONIBLE EN: HTTPS://WWW.CSIS.ORG/ANALYSIS/ENERGY-FACT-OPINIONINDIA-JOINS-INTERNATIONAL-ENERGY-AGENCY-ASSOCIATION-COUNTRY. CONSULTADO EL 15 DE MARZO DE 2019.

NARLIKAR, Amrita. New powers in the Club: the Challenges of global trade governance. International Affairs, v. 86, N. 3, p. 717-728, 2010. NOLTE, Detlef. How to compare Regional POWERS: ANALyticAl CONCEPTS AND ReSEARCh topics. Review of International Studies, v. 36, N. 4, P. 881-901, 2010. 
Las potencias emergentes en los espacios multilaterales de negociación...

NOSSEl, Suzanne. The world's rising powers have fallen. Foreign Policy, 2016.

OMC - Organización Mundial del Comercio. Declaración de Doha. 2001. DISPONIBLE EN: HTTPS://WWW.WTO.ORG/SPANISH/TRATOP_S/DDA_S/DOHAEXPLAINED_S. htm. Consultado el 16 de marzo de 2019.

RAUSTIALA, Kal; VICTOR, DaVID G. The REgIME COMPLEX For PLANT GenetIC resources. International Organization, v. 58, P. 277-309, 2004.

REUTERS HONG KONG. China CAMBIA SU LEy DE PATENTES PARA obTeneR fármacos baratos. Agencia de noticias Reuters Hong Kong, 13 junio 2012.

RUGGIE, John Gerard. International REgimes, transactions, AND CHANGE: EMBEDDED LIBERALISM IN THE POSTWAR ECONOMIC ORDER. INTERNATIONAL

Organization, v. 36, n. 2, International Regimes, P. 379-415, 1982.

SANAHUJA, José. Posglobalización y AsCenso de LA EXTRema dereChA: CRISIS de hegemonía y riesgos sistémicos. En: MeSA, Manuela (Coord.) Seguridad INTERNACIONAL Y DEMOCRACIA: GUERRAS, MILITARIZACIÓN Y FRONTERAS. ANUARIO 2016-2017. MADRID: CEIPAZ, 2017.

SCHWELLER, RANDALL L. BANDWAGONING FOR PROFIT: BRINGING THE REVISIONIST State back. International SeCurity, v. 19, N. 1, P. 72-107, 1994.

SCHWELler, Randall L. Emerging powers in an age of disorder. Global Governance, v. 17, N. 3, P. 285-297, 2011.

ShOeman, Maxi. South Africa as an emerging power: from label to 'status CONSISTEncy'? University of Pretoria, 2015. DisPonible EN: HTTPS://REPOSITORY.UP.AC.ZA/BITSTREAM/HANDLE/2263/51393/SCHOEMAN_ SOUTH_2015.PDF?SEQUENCE=1\&ISAlLOWED=Y. CONSULTAdo EL 7 DE FEBRERO DE 2018. 
SiDiROPOUlOS, Elizabeth et al. (eds.). Institutional Architecture and Development. Responses from emerging powers. Johannesburg: South African Institute of International Affairs (SAIIA), 2015.

SOUSA, Sarah-Lea John de. Brasil, India y Sudáfrica: potencias para un nuevo orden. Política Exterior, N. 121, p. 165-178, 2008.

STUENKEL, Oliver. 0 mundo pós-Ocidental. PotênCias emergentes e a NOVA ORDEM GLOBAL. RIO DE JANEIRO: ZAHAR, 2018.

The Medicines and Related Substances Control Act. Act nº 90. Sudáfrica, 1997. DISPONIBLE EN: HTTPS://WWW.NDA.AGRIC.ZA/VETWEB/LEGISLATION/ OTHER\%20ACTS/R_MEDICINES_AND_RELATED_SUBSTANCES.HTM. CONSULtAdO EL 16 DE MARZO DE 2019.

VAN DE GRAAF, ThiJs. Obsolete or Resurgent? The International Energy Agency in a changing global landscape. Energy Policy, v. 48, P. 233-241, 2012.

ViOlA, Eduardo; FRANCHINI, Matías; RIBEIRO, Thais Lemos. Sistema INTERNACIONAL DE HEgEMONÍA CONSERVADORA. GOVERNANÇA GLOBAL E democracia na era da crise climática. Annablume: São Paulo, 2013.

VReÿ, François. A Blue BRicS, Maritime Security, and the South Atlantic. Contexto Internacional, v. 39, N. 2, P. 351-371, 2017.

Wang, Yizhou. China's neW foreign Policy: tRanSformations and CHALlenges Reflected in changing discourse. Special Forum, School of International Studies, Peking University, 2014. Disponible en: http://www.theasanforum. ORG/CHINAS-NEW-FOREIGN-POLICY-TRANSFORMATIONS-AND-CHALLENGES-REFLECTEDIN-CHANGING-DISCOURSE/.

WOODS, Ngaire. Global governance after the financial CRISIS: a NeW multilateralism or the last gasp of the great powers? Global Policy, v. 1, N. 1, P. 51-63, 2010. ZAKARIA, Fareed. How America can survive the rise of the rest. Foreign Affairs, v. 87, N. 3, P. 18-43, 2008. 